\title{
La Inquisición en Écija
}

\author{
María Palacios Alcalde *
}

El Tribunal de la Inquisición fue creado por los Papas en la Edad Media y actuó en el conjunto de la Cristiandad con una excepción: el Reino de Castilla. En éste no se introdujo hasta el año 1478, cuando, a petición de los Reyes Católicos, lo estableció el Papa Sixto IV. En 1482 se erigió un Tribunal inquisitorial en la ciudad de Córdoba, al que se señaló, como ámbito de jurisdicción, un amplio territorio en el que estaba incluido el arcedianato de Écija ${ }^{1}$.

En sus primeros tiempos, la Inquisición actuó principalmente en la persecución de los judeoconversos, quienes, como se sabe, eran los judios que se habian convertido al cristianismo, de grado o por fuerza, así como sus descendientes directos. De la misma forma que las riquezas y el poder de los judíos habían estimulado el odio de los cristianos viejos, hubo un momento en que los conversos suscitaron una animosidad semejante, que se expresó en brotes de violencia y en horrorosas masacres.

Ya a finales del siglo xIV, Ferrán Martínez, arcediano de Écija, había movido con sus soflamas toda una tormenta persecutoria que cubrió de sangre judia todo el Reino de Castilla y provocó masivas conversiones

* UNED.

1 H. CH. LeA: Historia de la Inquisición española, t. I, Madrid, Fundación Universitaria Española, 1983, p. 790; remite a G. MATUTE I LuQuin: Colección de los Autos Generales y particulares de fe celebrados por el tribunal de la Inquisición de Córdoba, Córdoba, s.t., pp. 1 y 75. Para la geografía inquisitorial, véanse los trabajos de J. P. DEDIEU y J. Contreras: "Geografía de la Inquisición española: la formación de los distritos (1470-1820)": Hispania, 144, 1980, pp. 55-56; R. GARCiA: "La estructura territorial: primera delimitación", en J. Perez-B. Escandell: Historia de la Inquisición en España y América, t. I, Madrid, BAC, pp. 411-412; M. AvILÉs: Modificaciones territoriales, Ibidem, pp. 609-612. 
de judios ${ }^{2}$. Esto había ocurrido a partir de 1391, fecha en que la persecución se centró, cada vez más, contra los conversos. Como sus antepasados judíos, también los conversos acumularon riqueza y poder suficiente e incluso ganaron el favor de la nobleza; pero esto no impidió que, en el siglo $\mathrm{xv}$, volvieran a repetirse las matanzas que habían menudeado a finales del siglo anterior.

En Córdoba se desencadenó una gran masacre el 14 de marzo de 1473. Un incidente ocurrido durante una procesión desencadenó un motin. Entre don Alonso de Aguilar y su hermano, el futuro Gran Capitán, lograron sofocarlo momentáneamente, pero los cristianos viejos, favorecidos por el Conde de Cabra y el Obispo de Córdoba, volvieron a la carga. Después de una auténtica batalla que duró dos dias, los Fernández de Córdoba se refugiaron en el Alcázar, llevando consigo a los conversos y judios que pudieron. Los demás quedaron a merced de las turbas. Cuando se calmaron los ánimos, don Alonso logró un acuerdo con las autoridades de la ciudad, por el que se perdonó la vida a los supervivientes, con la condición de que se desterraran perpetuamente de la ciudad. No les valió gran cosa, pues, mientras se alejaban de Córdoba, fueron robados y asesinados por los caminos impunemente.

En aquellas trágicas jornadas intervinieron también gentes de los pueblos cercanos a Córdoba, labradores cristianos viejos. La noticia de lo ocurrido en Córdoba fue llevada por éstos tales a sus pueblos de origen. En algunos de ellos, la nobleza logró disuadir al populacho, como ocurrió en Écija, donde don Fadrique Manrique impidió los horrores de una matanza. No ocurriría lo mismo en otros lugares, como en Jaén, donde los cristianos viejos asesinaron a la primera autoridad de la Ciudad, el Condestable don Miguel Lucas de Iranzo y se lanzaron a una orgía de sangre que inundó la ciudad y los pueblos circunvecinos ${ }^{3}$.

Al parecer, el deseo de los Reyes Católicos de impedir esta «justicia popular" debió contar entre los motivos que les llevaron a crear un tribunal, como el de la Inquisición. De ahí que la Inquisición se cebara, en sus primeros años, en la persecución de los judeoconversos. De creer es, igualmente, que en esta misma etapa de su andadura, la Inquisición habría rastrillado Écija, como espulgó todo el país, en busca de judeocon-

${ }^{2}$ Cfr. J. Amador DE los Rios: Historia social, politica y religiosa de los judios en España y Portugal, Buenos Aires 1943, Libro Segundo, Capitulo VII.

${ }^{3}$ H. C. LEA, op. cit., t. I, p. 150. 
versos. Pero, desgraciadamente, no nos han quedado referencias a lo ocurrido en Écija en estas circunstancias. Como es bien sabido, los documentos originales, que debieron conservarse en el archivo de la Inquisición de Córdoba, desaparecieron en el siglo $x \mathrm{xX}^{4}$. Asi, cuanto hoy sabemos de lo actuado por la Inquisición córdobesa, lo hemos conocido por otros archivos, concretamente, el del Consejo de la Suprema y General Inquisición, conservado actualmente en el Archivo Histórico Nacional. Allí quedaron numerosas noticias en la correspondencia que mantuvo el Tribunal de Córdoba con su central, que lo era el Consejo, pero todas ellas son posteriores a las fechas que marcan la andadura inicial de la Inquisición, aquélla, precisamente, en que se reprimió especialmente a los conversos ${ }^{5}$.

Nuestro recorrido por la historia de la acción inquisitorial del Tribunal de Córdoba sobre las gentes de Écija, no se inicia sino en la segunda mitad del siglo XVI, cuando ya reina en la Monarquía Católica el Rey Felipe II.

Así, entre 1558 y 1730 , fecha de nuestras últimas referencias documentales, hemos logrado identificar hasta un total de ciento catorce personas, relacionadas todas ellas con Écija, que fueron sentenciadas por la Inquisición cordobesa por las más diversas causas. Si consideramos que el período estudiado abarca 173 años, a cada año habria correspondido una media matemática de 0,65 sentenciados por año. Al nivel en que se encuentran nuestros estudios sobre la actividad de la Inquisición en el distrito cordobés, podemos decir que el índice hallado para Écija es muy parecido al de Jaén $(0,68$ anual, con 113 procesados), pero se encuentra por encima de los índices de un Priego de Córdoba $(0,24$, con 40 procesados) 0 una Úbeda (con 0,42 y 67 procesados) $^{6}$.

${ }^{4}$ A excepción del Archivo Inquisitorial de Cuenca, que aún se encuentra in situ, los demás corrieron la suerte diversa, desde la destrucción a la fragmentación y dispersión de sus fondos. Sobre el particular, cfr. L. A. TEJADA: Ocaso de la inquisición, Algorta 1979; J. PINTO: "Los fondos manuscritos", en J. PEREZ, op. cit., pp. 58 ss.

${ }^{5}$ R. GRACIA BoIx ha publicado manuscritos relacionados con la Inquisición cordobesa en su Colección de documentos inéditos para la Historia de la Inquisición de Córdoba, Córdoba 1982 y en Autos de fe y causas de la Inquisición de Córdoba, Córdoba 1983. Los documentos que sirven de base a nuestra investigación proceden de los fondos del A.H.N. También existen fondos relacionados con la Inquisición cordobesa en el British Museum de Londres, sobre los que hay datos en M. AvILÉs: "Los fondos extranjeros", en J. PEREZ, op. cit., pp. 83-89 y E. LLAMAS: Documentación inquisitorial. Manuscritos españoles del siglo XVI existentes en el Museo Británico, Madrid 1975.

${ }^{6} \mathrm{Cfr}$. M. AvILEs: Estudio socio-estadistico de la represión ideológica en un ámbito local: La inquisición en Úbeda: Códice (Jaén) 1, 1985, p. 11. 
Si atendemos a los procesados en cada siglo, hallamos que el siglo $\mathrm{XV}$ I fue el más denso, pues se registran 101 procesados en los cuarenta $y$ dos años que se han estudiado en este siglo, en claro contraste con el siglo XVII, en el que no hallamos más que siete, o con el XVIII, en que la Inquisición sólo sentenció a seis astigitanos.

No nos detendremos, sin embargo, en esta ocasión, a presentar los cuadros estadísticos en que podría recogerse, con todos sus matices, la acción inquisitorial sobre Écija. Hemos preferido acercanos a un nivel más humano, el de las personas concretas que padecieron en su carne la presión de aquellos tiempos que ya santa Teresa dio en llamar «tiempos recios", los tiempos de la Inquisición.

En nuestra opinión, creemos que pueden diferenciarse tres grandes fases en la historia que presentamos. La primera de ellas se sitúa entre 1558 y 1592. Ninguna de las veintidós personas de cuyos casos tenemos noticia, fueron procesados por causa que tuviera que ver con el judaísmo y esta circunstancia es la que caracteriza esta primera fase. En la segunda, por el contrario, la inmensa mayoría fueron procesados por el delito de judaizar. Los conversos aparecen tanto en los autos de fe del resto del siglo XVI, como en los del XVII y el XVIII, dando un carácter claramente antijudaico a toda esta larga fase. La tercera, mucho más breve, se registra a partir de 1726. Ya no hay más rastro de conversos. Las pocas sentencias que a esas alturas registramos, se deben a otras razones distintas de las que predominaron en la etapa central de nuestra clasificación.

\section{PRIMERA ETAPA: LA VIGILANCIA SOBRE LOS CRISTIANOS VIEJOS}

En la primera de las etapas que hemos distinguido, la acción inquisitorial viene a incidir, como dijimos, de forma predominante, sobre la población de cristianos viejos de Écija. Es algo semejante a lo que ocurrió en el resto de la Monarquía. Pasada la primera racha de persecución al converso, la Inquisición se volcó sobre la población de cristianos de toda la vida, los "cristianos viejos o cristianos lindos", como se les llamaba. La aparición del peligro protestante y la aplicación de las normas establecidas por el Concilio de Trento, condicionan un esfuerzo de la 
iglesia y del Estado por controlar a sus súbditos, del que es consecuencia la actividad procesal que aquí se muestra.

¿De qué crimenes podian ser acusados los cristianos ante la Inquisición? No esperemos espectaculares actos de delincuencia ideológica. Lo que llevó a los ecijanos de la época a las cárceles inquisitoriales fueron actos por los que hoy nadie se escandalizaría. Veamos algunos ejemplos.

El curtidor Francisco Poley fue condenado a oír una misa y a pagar una multa, por haber dicho "palabras desatacadas"; otro tanto ocurrió a Juan Vidal, hortelano, por haber dicho "palabras contra el poder de Dios". Otros tres compadres de los susodichos, el sastre Luis Tostado, el tinajero Bartolomé y el tratante Pedro de Aguayo, fueron acusados de haber dicho palabras heréticas, erróneas o sospechosas, pero no debieron ser mucho más graves que las de los primeros, porque las penas que se les impusieron fueron muy parecidas a las de aquéllos. Peor suerte corrió el ciego Benito Sánchez, azotado por embaucador o un lego carmelita, llamado fray Juan, a quien, por haber dicho misa sin estar ordenado, lo condenaron a azotes y a ser encarcelado en su monasterio ?.

Las primeras referencias explícitas a la presencia de ecijanos en los "Autos de fe" corresponden a 1563. Se celebró uno en la Catedral de Córdoba el 24 de octubre. De los seis sentenciados, uno era de Écija, el arriero Luis Jiménez, a quien se le hizo abjurar como levemente sospechoso de herejía y se le expuso a la vergüenza pública con una soga atada al cuello. Su delito fue el de haber afirmado "que no era pecado mortal tener acceso carnal a una mujer estando fuera de su tierra, pagándoselo». Se trataba del delito conocido como «proposiciones sobre simple fornicación". La Inquisición y, por su medio, la Iglesia, trató de inculcar en sus fieles el mayor respeto al matrimonio y creyó contribuir a conseguirlo castigando de esta forma, no a quienes cometían fornicación, pecado que se lavaba en el confesionario, sino a quienes afirmaban que no era pecado mortal el realizarla ${ }^{8}$.

\footnotetext{
7 A.H.N., Sec. Inq., leg. 2392-1. Cfr. R. Gracia: Autos..., pp. 22, 23 y 25.

${ }^{8}$ Cfr. R. Gracia: Autos..., p. 28.
} 
En los años siguientes, hay noticias de diversos ecijanos penitenciados por delitos similares. Nos abstendremos de enumerarlos en detalle. Destacaremos casos tales como el de Alonso de Carmona, penitenciado

“... porque, queriéndose uno ir a confesar sólo, se tornó diciéndole que se hincase de rodillas en el campo, que también le oirian allí de penitencia como un clérigo" ${ }^{9}$.

Nuevamente encontramos la atención inquisitorial a la buena doctrina sobre los sacramentos, cuya naturaleza había sido definida por el Concilio de Trento. No sólo se protege el matrimonio, como vimos en el caso anterior; aquí vemos cómo se defiende la confesión. Todo ello se encaminaba a contrarrestar la doctrina protestante, para la cual los sacramentos, como todo lo que pudiera mediar entre el hombre y Dios, más que una ayuda, se consideraban un obstáculo.

En la década de los setenta del siglo XVI aparecen también, por primera vez, por lo que a Écija se refiere, datos acerca de gentes penitenciadas por haber adoptado creencias o prácticas propias del islamismo. En general se trata de moriscos esclavizados o deportados como consecuencia de la victoria del Estado sobre los rebeldes de las Alpujarras. El primer caso de que tenemos constancia fue el de Diego Hernández, herrero morisco, de 35 años, vecinos de Ecija. Estaba rezando un dia ante una imagen de la Virgen cuando alguien se le acercó a persuadirle para que se pusiera de rodillas. El morisco, indignado, tiró su sombrero al suelo y prorrumpió en palabras, dichas en algarabía. De lo poco que se le debió entender se dedujo que "había dicho que no se le daba dos maravedís", entre otros exabruptos semejantes. Se le condenó a tres años de galeras, con lo que el Rey pudo disponer de un remero más para su flota de Levante, encargada de contener la amenaza del turco ${ }^{10}$.

Junto a estas rutinas delictivas, no faltan tampoco penitenciados a quienes se castiga por haber abusado del poder que, por aquel entonces, ya ha concentrado en sí la Inquisición. Tal fue el caso de un abogado de Écija, el doctor Francisco de Villacreces a quien se acuso de que un día, cuando iba a prender a un hombre, acompañado de su hijo el licenciado

\footnotetext{
${ }^{9}$ A.H.N., Sec. Inq., Leg. 1856-1, exp. 13, fol. 5, v. R. Gracia: Autos..., p. 151-152.

10 Id, Ibidem, p. 167-168.
} 
Antonio de Villacreces, con un mandamiento de la justicia civil, tuvo la ocurrencia de convencer a su hombre para que se diese preso dándole a entender que venía a prenderlo en nombre de la Inquisición. No era la primera vez que abusaba de su condición familiar de la Inquisición. Se dijo que, en otra ocasión, yendo en una procesión, se había enfrentado con quienes la presenciaban, ordenándoles que se hincasen de rodillas porque lo mandaba su hijo, que era consultor del Santo Oficio. Probablemente no se trataba más que de un pobre diablo presuntuoso; pero tanto él como su hijo fueron condenados a destierro temporal y a unas multas más bien cargadas ${ }^{11}$.

La mayor parte de los sentenciados en esta primera fase son varones. En la siguiente etapa, por el contrario, las mujeres constituyen una abrumadora mayoria. Si atendemos a las profesiones de los reos, encontramos un claro predominio de gentes dedicadas a lo que hoy denominamos "sector secundario". Hallamos entre ellos curtidores, sastres, tinajeros, herreros y cocineros. En lo que llamariamos el sector terciario o de servicios, aparecen arrieros o aguadores. La proporción en que figura el "sector primario" es, sin embargo, notable. Menudean los labradores, hortelanos y trabajadores en una proporción que destaca sobre lo que hemos detectado en otras poblaciones del mismo distrito inquisitorial cordobés ${ }^{12}$.

\section{SEGUNDA ETAPA: LA REPRESIÓN DE LOS JUDAIZANTES}

Por estos cauces de relativa tranquilidad discurria la acción inquisitorial sobre Écija, cuando se desencadenó la psicosis anticonversa, a la altura de 1593. Por estas fechas, Écija contaba con unos 6.000 habitantes. El control inquisitorial lo ejercía un equipo formado por dos comisarios, un notario y diez familiares ${ }^{13}$. Los comisarios habian recibido, ya

11 Id, Ibidem, p. 205.

${ }^{12}$ Cfr. M. AVILÉs: Estudio socio-estadístico... p. 11

13 A.H.N., Sec. Inq., leg. 2402 (Carta del Tribunal al Consejo de 24 nov. 1610). En este documento se envía una "Particular relación..." en la que, junto al nombre de cada pueblo, se hace referencia al número de vecinos y al de comisarios, notarios y familiares que a cada uno de ellos les corresponde, de acuerdo con la Carta Acordada de 24 de marzo de 1604. 
con anterioridad, algunas denuncias contra presuntos judaizantes, que no habían logrado concretarse en procesos. Mas, en esta ocasión, se produjo un hecho que provocó una lluvia de delaciones: la visita realizada a Écija por el doctor don Alonso Jiménez de Reinoso, inquisidor de Córdoba.

De las vicisitudes de esta visita nos ha dado noticia J. Aranda ${ }^{14}$. Pero de la complejidad de cuanto ocurrió en aquellas fechas, con sus intrincadas ramificaciones y consecuencias, es poco lo que sabemos, debiendo constatar que ni siquiera en una reciente Historia de la Inquisición en España y América se haya dedicado una sola página a unos acontecimientos verdaderamente significativos, dentro de la historia del criptojudaísmo hispano ${ }^{15}$.

Por lo que el propio inquisidor nos cuenta, Reinoso realizó su visita en dos etapas. La primera duró "cuatro meses y algunos días más", pero todo este tiempo no le bastó para completar su cometido. Sin contar con él, sus colegas, los otros inquisidores cordobeses, ordenaron la prisión de los encartados por judaizantes, con lo que no se pudo dar un rápido carpetazo al asunto. La propia ciudad de Écija, interesada en que todo se resolviera con sigilo y rapidez, suplicó al Inquisidor General pidiéndole que enviara allí "quien lo acabase". Desde Madrid dieron orden de volver al propio Reinoso.

«Detúveme de esta segunda ida a la dicha ciudad, -contaría después Reinoso-, casi cuarente dias y, en ellos, a lo que se pudo entender, quedaron acabados todos los negocios que de presente se ofrecian y se trajeron formadas setenta y dos causas, que todas ellas han de ser de Auto Público." ${ }^{16}$

En realidad, no fueron tantos los encausados que, en los años siguientes, aparecerian en los Autos públicos de fe, como pronosticara el inquisidor Reinoso. En mayo de 1595, veintinueve ecijanos estuvieron

14 J. ARANDA DONCELL: "La Inquisición de Córdoba: Visita a Écija en 1593 y actuación sobre los judaizantes": Bol. de la Real Academia de Córdoba... LIII, 104, 1983, pp. 5-18.

${ }^{15} \mathrm{Cfr}$. H. C. LeA, op. cit., t. Ill, p. 22; A. Dominguez Ortiz: Los judeoconversos en España y América, Madrid 1971, p. 58.

16 A.H.N., Sec. Inq., leg. 2396 (Carta del Inquisidor Reinoso al Consejo, de 10 sept. 1594. Cfr. APÉNDICE DOCUMENTAL, I. 
presentes en el solemne auto que se celebró en la Plaza de la Corredera de Córdoba. En marzo de 1597, otro Auto de fe, celebrado igualmente en la Corredera, presentó al público veintidós judaizantes de Écija. Todavia en 1598, aparecen otros dos en el auto que se celebró entre los dos coros de la Catedral. En total, no llegaron a los sesenta ${ }^{17}$. ¿Qué había ocurrido entre 1593 y 1598 ? Momento hubo, en el proceso, en que los encargados superaron los cuatrocientos individuos ${ }^{19}$. ¿Cómo es que las sentencias que resultaron de lo que el comisario de Écija denominó "la complicidad de los judaizantes", fueron, relativamente, tan escasas?

Es imposible profundizar, en el corto espacio de que disponemos, en los complicados entresijos de este proceso masivo de judaizantes que, en cierto momento, llegó a convertirse en un verdadero proceso a la ciudad entera. Asi lo entendieron los propios ecijanos que, llegaron a deputar a uno de sus regidores para que fuera a Madrid a gestionar ante el propio Felipe II un indulto general. Es más, el propio rey llegó a pedir y a conseguir del Papa que expidiera un breve, en 1597, en que absolvía a los judaizantes de sus delitos, personaba a cuantos estaban a la espera de juicio, los libraba de toda infamia a ellos y a sus descendientes e incluso concedia un "período de gracia" de cuatro años, durante los cuales, cuantos acudieran a la Inquisición arrepentidos de haber judaizado, podrian gozar de todos estos privilegios ${ }^{19}$.

No sabemos qué fue lo que movió a los poderes públicos, civiles y eclesiásticos, a tratar con tal inesperada benevolencia a los judaizantes ecijanos. Cierto es que en aquella "complicidad" estaban implicados en Dersona o por familiares cercanos, los prohombres de Écija, regidores, jurados, escribanos, etc. Se encontraron ramificaciones en Madrid y en numerosos pueblos y ciudades de Andalucía. La influencia de los poderosos debió incidir, indudablemente, en la relativa suavidad de las sentencias que se les aplicaron ${ }^{20}$. Pero, al mismo tiempo, también hay que tener en cuenta el temor que sacudió a toda la ciudad de Écija de quedar infamada colectivamente, por lo que se hizo todo lo posible por aplacar el escándalo, buscando soluciones rápidas y sigilosas antes de que estallara el polvorín cuya mecha habían encendido los testimonios recibidos por el inquisidor Reinoso, en su visita de 1593.

\footnotetext{
17 A.H.N., Sec. Inq., leg. 1856-1, exp. 41 , fol. 6 v. y ss. En R. Gracia: Autos... p. 345.

18 A.H.N., Sec. Inq., leg. 2396 (Carta del Inq, Reinoso al Consejo).

19 H. C. LEA, Op. cit., t. III, p.22.

${ }^{20}$ Cfr. A. Dominguez Ortiz: op. cit., p. 59-60.
} 
Hay varios aspectos en esta "complicidad" que nos parecen especialmente dignos de destacarse por cuanto que difieren notablemente de otros casos similares que se registraron a lo largo de la historia inquisitorial. Sorprendente es el que, entre las mujeres acusadas y condenadas por haber judaizado, aparezcan numerosas "beatas", algunas de ellas tenidas incluso por santas ${ }^{21}$. En 1590 había tenido lugar, en Córdoba, un célebre Auto de fe en el que se sacaron al público las extravagancias de otras beatas, condenadas por "alumbradas" ${ }^{22}$. Solamente en Écija hemos encontrado esta singular mezcla, de beatas judaizantes.

Sorprende, igualmente, encontrar judaizantes entre los labradores. Excepcionales son los casos de judíos dedicados a actividades propias del sector primario. Aquí, en Écija, los encontramos. Al parecer, los indujeron a judaizar los conversos ecijanos y este es otro aspecto singular, pues bien sabido es que los judios - y creemos creer que también los judaizantes-, no hacian ni hacen proselitismo religioso ${ }^{23}$.

Estos detalles, unidos a los que hemos enumerado sobre el carácter masivo de este movimiento, sus ramificaciones en otras áreas geográficas y su vigencia entre la oligarquía rectora de la ciudad de Écija, hacen de éstos hechos un acontecimiento único, merecedor de un estudio más profundo, al que nos hemos comprometido y en el que nos hallamos empeñados.

Nuevamente hallaremos criptojudíos en el siglo XVII. En 1655, un nuevo Auto de fe. celebrado también en la Plaza de la Corredera, llevó ante el Tribunal a cinco varones y dos hembras por judaizantes. En este caso, se trató, predominantemente, de criptojudíos portugueses, onmipresentes en todos los tribunales inquisitoriales desde su penetración masiva en España en tiempos del Conde Duque de Olivares ${ }^{24}$.

La última andanada contra los conversos se registra en el siglo XVIII. Portugueses 0 descendientes de portugueses, pero nacidos ya en España, son casi todos los encausados que aparecen en los Autos de fe

21 Véase nuestro trabajo "Las Beatas ante la Inquisición" en Hispania Sacra, Tomo VI, pp. 107-132, Madrid 1988.

${ }^{22}$ A.H.N., Sec. Inq., Leg. 1856-1, exp. 33; R. Gracia Bolx: Autos..., p. 224; A. Huerga: Historia de los alumbrados, t. II, Madrid 1978, pp. 617-623.

${ }^{23}$ Cfr. J. L. RuIz Vera: El mundo rural ante la Inquisición (Lección presentada al Curso de Verano de la Universidad de Córdoba, en prensa).

${ }^{24}$ Cfr. J. Pérez, op. cit., t. I, p. 897. 
de 1723 y 1724 . Como en otros lugares de España y, sobre todo, en Andalucia, también entre los judaizantes de Écija se descubre, en esta ocasión, que son gentes dedicadas, principalmente, al comercio de productos coloniales (azúcar, chocolate, especias) o a la administración del monopolio de tabacos ${ }^{25}$.

En el de 1723 fue relajado Miguel de Soto y Herrera, nacido en Burdeos y establecido en Écija como mercader. Su caso no parece ser el de un hombre aislado. Se le relaciona con un estanquero de tabacos, de Baños de la Encina, en la provincia de Jaén, condenado en otro Auto de fe en 1721. Se le relaciona, también, con el matrimonio formado por Manuel de Villarreal y Ana de Soto y Herrera, estanqueros de Aguilar, condenados también en 1721. A su vez, éstos conectan con otro matrimonio de judaizantes, Diego de Herrera y Leonor de Varillas, botoneros en Córdoba, que fueron condenados, junto con sus tres hijas, en el Auto de fe de 1722. Pero las ramificaciones de esta pequeña tribu de judaizantes no acaba aquí. Todavía se les puede relacionar con otra familia de estanqueros cordobeses, a la que pertenecía Catalina de Reina y Medina, natural también de Burdeos, condenada y reconciliada ya a finales del siglo XVII, que, en 1722, fue relajada a la justicia seglar por el Tribunal de Córdoba. La crónica de este Auto nos cuenta cómo Catalina:

«... fue relajada a la justicia seglar por judaizante, convicta, negativa, y antes confesó y dio señales de contrición y arrepentimiento" ${ }^{26}$.

Los dos últimos casos de judaizantes ecijanos corresponden, como hemos adelantado, al auto de 1724. En este caso se trató de dos hermanas, Catalina María de Ribera, aguardentera de Écija y Serafina de Ribera. De esta última sabemos que era estanquera de tabaco en Écija, soltera de cincuenta y dos años. Estando presa en las cárceles de la Inquisición, enfermó y murió; arrepentida de haber judaizado, se le permitió recibir los últimos sacramentos. No pudo acudir en persona al Auto de fe, pero la representó una estatua, colocada sobre una pértiga. Sus bienes fueron confiscados por la Inquisición ${ }^{27}$.

${ }^{25} \mathrm{Cfr}$. Auto de 1723: Biblioteca Nacional de Madrid, sign. R.2725. Auto de 1724, Ibidem, R.8560-3.

${ }_{26}$ Auto de 1726 en BN de Madrid, R.2825-32; R. Gracia: Autos..., p. 518; Auto de 1730, BN de Madrid, VC, 294-39; R. Gracia: Autos..., p. 521.

27 R. Gracia: Autos..., p. 515. 


\section{LOS ÚLTIMOS ENCAUSADOS}

Desde la última fecha indicada hasta la extinción de la Inquisición, ya o se procesaría en Écija a ningún otro judaizante. En esta etapa final de la Historia de la Inquisición, coincidente con el auge de las ideas ilustradas en España, los procesados por cualquier tipo de delito son cada vez más escasos. Nosotros no hemos hallado más que dos, uno en 1726 y otro en 1730 .

En el Auto de fe de 1726 compareció un tal José Sánchez de Ribera, natural de Málaga, que se dedicaba en Ecija al oficio de tonelero. Se le encausó por haber intentado contraer un segundo matrimonio cuando aún vivía su primera mujer. Se le condenó entre otras penas a la de destierro de Écija, Málaga y Madrid durante ocho años; los cinco primeros, además, debia cumplirlos como remero de las galeras reales, sin cobrar por ello sueldo alguno. Además, al día siguiente del Auto, tuvo que pasar por la vergüenza de recibir doscientos azotes, que el verdugo la propinó mientras lo paseaban por las principales calles de Córdoba ${ }^{28}$.

Finalmente, en 1730, salió al Auto de fe María Inés Guerrero de Gálvez, natural de Aguilar y vecina de Écija, donde trabajaba como costurera. Se le acusó de poligamia; su pena, sin embargo, fue mucho más suave que la aplicada al tonelero de que hemos hablado: se le reprendió públicamente; se le paseó con una vela en la mano, vestida de penitente; se le desterró, durante seis años, de Córdoba, Écija, Aguilar, Baena y Madrid. Pero su condición femenina le sirvió para librarse de lo que no se pudo librar el tonelero: batir el remo de una galera al servicio de su Majestad Católica ${ }^{29}$.

En nuestro rápido recorrido por la historia de la acción inquisitorial sobre la ciudad de Écija, es obvio que hemos tenido que dejar a un lado otros muchos aspectos importantes, al fijarnos, preferentemente, en los aspectos procesales. Podriamos atender, igualmente, a las estructuras organizativas permanentes, es decir, al "personal» afecto a la Inquisición que residió permanentemente en la ciudad y se encargó de vigilar a sus convecinos y a delatarlos, llegado el momento. Dejamos, igualmente,

28 R. Gracia: Autos..., p. 608.

29 R. Gracia: Autos..., p. 526. 
para mejor ocasión, el estudio de las relaciones entre la «realidad social» de la ciudad y el apoyo prestado a la Inquisición. Pasamos, igualmente, por alto, el estudio de las inspecciones o visitas que, con carácter extraordinario, realizó la Inquisición sobre Écija, a lo largo de su historia. La documentación que podria ilustrarnos sobre todos estos aspectos, aun mutilada y lacunar, es abundante; de su estudio esperamos sacar respuestas a éstas y a otros muchos de los interrogantes que nos sugiere la problemática de la historia de las ideas y la historia de la represión que ejerció la Inquisición sobre las mismas, a lo largo de más de trescientos años. 


\title{
APÉNDICE DOCUMENTAL
}

\begin{abstract}
I
Carta de Alonso Jiménez de Reinoso, inquisidor en Córdoba, al Consejo de la Inquisición
\end{abstract}

10 de septiembre de 1594

«El año pasado de noventa y tres, para cumplir con la obligación ordinaria de la visita, salí a la ciudad de Ecija, donde por el Tribunal se habia acordado que se hiciese la primera sesión. $Y$ como los negocios de aquella ciudad se fueron extendiendo, tuve necesidad de detenerme allí los cuatro meses y algunos días más y aún si no se divirtiera el negocio con las prisiones que en aquel mismo tiempo, contra mi parecer, mandaron hacer mis colegas, procurara acabar de todo punto lo que había que hacer antes que de alli saliera, porque, por no quedar acabado, la misma ciudad, en principio de este año, suplicó a V.S. mandasen enviar allí quien lo acabase y fueron servidas de mandarme a mí que fuese a ello. Detúveme, de esta segunda ida a la dicha ciudad casi cuarenta días y en ellos a lo que se pudo entender quedaron acabados todos los negocios que de presente se ofrecian y se trajeron formadas setenta y dos causas que todas ellas han de ser de Auto Público, como lo habrán visto V.S. por la relación que de ellas se envió. Los finales del mes de junio pasado. $Y$, sin esto, se leyeron editos y se hicieron otras diligencias, con las cuales en alguna manera se cumplió por hogaño con la visita ordinaria y afirmo a V.S. que en el trabajar no se perdonó aldea, mala noche, ni ahora se hace menos, porque es todo bien menester. Púsome aquella jornada en ocasión de gastar más de lo que ordinariamente gastara en mi casa $y$, como no soy rico, obligame la necesidad a suplicar a V.S. manden 
en esta contemplación hacerme la merced que fueren servidos. Dios guarde a V.S. muchos años, etc. De Córdoba 10 de setiembre 1594».

(A.H.N., Sec. Inq., leg. 2.396 (10.9.1594). 